\title{
What is Hacking's Argument for Entity Realism?
}

\author{
(Forthcoming in Synthese)
}

\section{Boaz Miller}

\begin{abstract}
According to Ian Hacking's Entity Realism, unobservable entities that scientists carefully manipulate to study other phenomena are real. Although Hacking presents his case in an intuitive, attractive, and persuasive way, his argument remains elusive. I present five possible readings of Hacking's argument: a no-miracle argument, an indispensability argument, a transcendental argument, a Vichian argument, and a non-argument. I elucidate Hacking's argument according to each reading, and review their strengths, their weaknesses, and their compatibility with each other.
\end{abstract}

Keywords Scientific Realism; Entity Realism; Inference to the Best Explanation; Transcendental Arguments; Indispensability Arguments; Scepticism

\section{Introduction}

Ian Hacking's Entity Realism (ER) is an influential position within the Scientific Realism (SR) debate. According to ER, unobservable entities that scientists carefully manipulate to study other phenomena, such as electrons that physicists spray from an electron gun, are real. Although Hacking presents his case in an intuitive, attractive, and persuasive way, his argument for ER remains elusive. I suggest five interpretations of Hacking's argument for ER: a no-miracle argument (NMA), an indispensability argument, a transcendental argument, a Vichian argument, and a non-argument. ${ }^{1}$ I draw the distinctions between these different kinds of argument based on the different epistemic warrants they supposedly enjoy.

Within this paper, I am less interested in the question of which reading most accurately captures Hacking's intentions, and more with the question of which reading best supports ER. But I acknowledge that any answer to the latter should be true to the former's spirit. The next

\section{B. Miller $(\bowtie)$}

The Sidney M. Edelstein Center for History and Philosophy of Science, Technology and Medicine, The Hebrew University of Jerusalem, 9190401, Israel.

The Graduate Program in STS, Bar Ilan University, Ramat Gan, Israel, 5290002.

e-mail: boaz.miller@gmail.com

${ }^{1}$ ER is associated with other scholars as well (Cartwright 1983; Giere 1988). This paper is devoted solely to Hacking. 
section reviews SR and situates ER within it. The subsequent sections respectively discuss the five different interpretations, and the last section examines the extent to which the different arguments can work together making a robust case for ER.

\section{ER within SR}

Roughly, SR states that science aims at discovering the truth about nature, and succeeds in attaining this aim. A more precise characterization of SR is as a conjunction of three theses, divided into six sub-theses:

Metaphysical:

(M1) There exists a mind-independent world.

(M2) This world has a unique structure.

\section{Semantic:}

(S1) Scientific claims, particularly about unobservables, should be taken at their face value; namely, they should be interpreted as purporting to literally describe the furniture of a mind-independent world.

(S2) Whether scientific claims are true or false is determined by the actual state of affairs in the world, independently of our ability to test of verify it;

Epistemic:

(E1) The aim of science is attaining the truth about nature, particularly about the unobservable world.

(E2) Mature empirically successful scientific theories achieve this aim, or come close to achieving it; namely, mature empirically successful scientific theories are true or approximately true of their intended domains. ${ }^{2}$

Different scholars parse these sub-theses slightly differently, but this threefold division is now standard (Chakravartty 2013). Some clarifications and contrasts are in order. Some of the sub theses contrast SR with commitments of antirealist positions. (M1) is contrasted with the

\footnotetext{
${ }^{2}$ My subsequent mentions of truth should be understood as referring to approximate truth as well.
} 
idealist denial of the existence of an external world, and with Kantian perspectivism, which holds that experienced reality is inescapably mediated by human cognition. (M2) rejects nominalism, which denies a natural grouping of the world into essences or kinds. (S1) rejects logical empiricists' and classic instrumentalists' view that observable terms are mere shorthand for describing observable phenomena. (S2) states a non-epistemic theory of truth. It is contrasted inter alia with verificationism, which states that the truth value of claims depends on their verification method. For satisfying (S2), realists typically adhere to a correspondence theory of truth, according to which claims are true if they correspond to the actual state of affairs in the world, and false otherwise. SR is committed to some form of correspondence between scientific claims about unobservables and reality, but some realists subscribe to a deflationary account of truth, and shoulder the burden of correspondence in other places, such as one's theory of reference, or a theory of truth-making. ${ }^{3}$ (E1) is contrasted with constructive empiricists' view that the aim of science is empirical adequacy, i.e., attaining the truth only about observable phenomena, and with classic instrumentalists, who posit merely providing useful tools for prediction and control as the aim of science. (E2) expresses epistemic optimism about science meeting its aim. Not all scientific realists accept all the above sub theses. Thus, there are many possible partly realist positions, because the number of possible combinations that accept only some of these sub theses is large.

A strong argument for SR is NMA. Its most famous formulation is by Putnam $(1975,73)$ : “The positive argument for realism is that it is the only philosophy that doesn't make the success of science a miracle". NMA ties together empirical success, reference of theoretical terms to unobservable entities, and truth. NMA is an inference to the best explanation (IBE). Under the IBE model, we legitimately infer the truth of our best explanation of some given facts. Explanatory merits such as simplicity and scope determine which explanations are the best. Explanatory considerations determine plausibility, so the best explanation is the likeliest

\footnotetext{
${ }^{3}$ I thank Anjan Chakravartty and an anonymous reviewer for this clarification.
} 
explanation (Lipton 2004). NMA states that there are only two possible types of putative explanations for the empirical success of science: explanations that appeal to the truth of science, or miraculous explanations. Because putative explanations that appeal to the truth of science is deemed a superior explanation to a miracle, we legitimately infer their truth.

An antirealist argument against NMA is the pessimistic induction (PI), which challenges the relations between success, reference, and truth. Laudan (1981) gives a long list of theories from the history of science which were empirically successful yet false and contained nonreferring terms. One way to construct Laudan's PI is as an enumerative induction:

(PI0) Since all past empirically successful scientific theories are false, it is likely that present empirically successful theories are also false.

An arguably better way to construct the argument (Lehoux 2012, 207) is as a reductio of NMA:

(PI1) If NMA is right, then very nearly all empirically successful theories will be true.

(PI2) But we have a long list of false successful theories.

(PI3) Therefore, NMA is false.

A common realist response to PI is selective scepticism, i.e., drawing a principled distinction between the true, belief-worthy elements of empirically successful theories, which tend to be preserved from old to new theories, and the false, belief-unworthy elements, which tend to be discarded. As Chakravartty $(2007,29)$ puts this:

As in life generally, so too in science: do not believe everything you are told. Not all aspects of scientific theories are to be believed. Theories can be interpreted as making many claims about the nature of reality, but at best one has good grounds, or epistemic warrant, for believing some of these claims. Only some aspects of theories are likely to be retained as the sciences march on.

Selective scepticism comes in many flavours. A notable example is Kitcher's $(1993,149)$ distinction between a theory's working posits, which employ theoretical terms that refer to real 
unobservable entities, and presuppositional posits, which do not. Various versions of structural realism also try to distinguish between the true elements of mature theories, and all the rest.

ER enters the picture here, as an influential version of selective scepticism. Hacking's (1983, Ch.16) ER makes two distinctions: between theories and entities, and between two kinds of unobservable entities: experimental entities and theoretical entities. Hacking argues for realism only about experimental entities. Experimental entities are entities that scientists manipulate to study other phenomena. Electrons are experimental entities, because experimental physicists spray them to study weak neutral currents, which are theorized to be carried by bosons. A slogan Hacking coins for ER is "if you can spray them then they are real" $(1983,23)$. In addition to the fact of their existence, Hacking $(1983,265)$ argues that we can know a modest number of "home truths" about experimental entities, which consist of thinly theory-laden low-level generalizations about their well understood causal properties; for example, their mass, spin, and charge. Hacking contrasts these low-level generalizations or "home truths" with full-blown scientific theories about unobservables, which are not belief-worthy.

ER in not an innocent doctrine. It significantly narrows the scope of SR. While ER leaves in electrons, photons, protons, and positrons, it leaves out neutrino, bosons, and black holes (Hacking 1989), as well as theories as such, as opposed to the entities that populate them. Its modesty arguably makes ER a more defensible position, but it dissatisfies many realists, who would like SR to have a wider scope.

In sum, Hacking's ER draws a clear distinction between observable and experimental entities, about which realism is warranted, and everything else. Hacking's argument for ER, however, is less clear. In what follows, I consider five interpretations of his argument, starting with NMA.

I stress that within this paper, I distinguish argument types on an epistemic basis, rather than structural. I distinguish argument types based on the type of epistemic warrant the argument confers on its conclusion. I am aware that there are other ways of drawing the boundaries between arguments. I also acknowledge that the distinctions may not be as clear-cut 
as I present them. My choice of terminology for classifying arguments types, however, should not hinder my substantive point, which is that it is possible to interpret Hacking's argument in five ways that differ significantly in the type of epistemic warrant they enjoy.

\section{The NMA Interpretation}

The first interpretation of Hacking's argument for ER is as NMA. Recall that under the IBE model, we legitimately infer the truth of our best explanation of some given facts. But why are we entitled to treat explanatory merits as likeliness indicators? There are various possible answers to this question, but within this paper, I adopt the view that our justification for doing so is empirical and context relative, specifically, relative to our background knowledge. On this view, IBE does not name a formal inference, but an abstract pattern whose force and success depend on the specific background assumptions involved, and whose specific form changes with context. Explanatory merits are empirical observations. For example, if a court infers a defendant's guilt from the fact that her fingerprints were found in the crime scene, a person matching her description was seen fleeing the crime scene, etc., this inference reflects the court's knowledge of how crimes are usually committed. Generally speaking, we observe regularities, see that some events are more frequent than others, and develop our explanatory merits based on these observations (Ben-Menahem 1990; Day \& Kincaid 1994).

Against PI, realists may argue that not all empirical success is the same. Realists may distinguish weak from strong or genuine empirical success. According to this view, truth explains empirical success only if "empirical success is robust, significant enough (sufficiently novel and abundant to be in need for explanation), and truth is a good [putative] explanation" (Solomon $2001,25)$. Realists may insist that while there may be other good explanations of weak empirical success, truth is the best and only explanation of genuine success.

If realists want to take this route, however, they face a twofold challenge. They need to show (1) that their criteria for genuine empirical success are principled and non-question begging, i.e., not constructed ad hoc to favour current science; (2) that we, unlike past historical 
actors, are in a privileged epistemic position to distinguish genuine success from weak success (Lehoux 2012, 206-220). Hacking's argument for ER may be interpreted as rising to this twofold challenge, and reconstructed as follows:

(NMA1) Contemporary experimental physicists' success in manipulating experimental entities to study other phenomena is much more impressive than previous empirical successes in the history of science in a way that makes it qualitatively different from it.

(NMA2) ER is the only philosophy that doesn't make this success a miracle.

(NMA3) Therefore, ER is true.

Some textual evidence supports this interpretation. Clearly, Hacking thinks that current experimental practice is qualitatively different from that of the $19^{\text {th }}$ century and before, such that it can support realism in a way that previous practice could not: "Anti-realism about atoms was very sensible ... a century ago. Anti-realism about any sub-microscopic entities was a sound doctrine those days" (1983, 274; emphasis in the origin). "Assumptions about the minute structure of matter could not be proven then. The only proof could be indirect... Such indirectness need never produce conviction in the philosopher inclined to instrumentalism or some other brand of idealism" $(1983,173)$.

Hacking writes that we have "evidence" and "proof" for the reality of experimental entities. The most straightforward logical inference structure in which Hacking's claims about experimental practice function as evidence is IBE. Yet Hacking seems to deny that his argument is an IBE, which seemingly makes the NMA interpretation a non-starter:

The argument... is not that we infer the reality of electrons from our success. We do not make the instruments and then infer the reality of the electrons, as when we test a hypothesis, and then believe it because it passed the test. That gets the time-order wrong. By now we design apparatus relying on a modest number of home truths about electrons to produce some other phenomenon that we wish to investigate $(1983,165)$. 
Once upon a time the best reason for thinking that there are elections might have been success in explanation... I have said that ability to explain carries little warrant of truth... Luckily we no longer have to pretend to infer from explanatory success (i.e. from what makes our minds feel good). Prestcott et al. don't explain phenomena with electrons. They know how to use them $(1983,271-272)$.

Nevertheless, I think the NMA interpretation is viable. We may distinguish the type of scientific activity that best supports the reality of electrons (theoretical explanation versus experimental manipulation) from the type of argument Hacking is giving for their reality (IBE versus another type of argument). The explananda of scientific explanations are specific phenomena associated with electron theories, while the explananda of the NMA are "science itself and its history of empirical success as a whole" (Ladyman 2014). Clearly, Hacking denies that mere explanatory success of electron theories supports the reality of electrons. This does not mean that his own argument is not an IBE. Hacking's argument may still be read as a NMA.

The NMA reconstruction constitutes a prima facie strong argument for SR. It takes the sting out of PI, by narrowing the base of the induction in its inductive formulation (PI0), or denying premise (PI1) in the reductio formulation. Additionally, its conclusion is strong - it states the reality of electrons, rather than merely that the belief in their reality is rational. The NMA reconstruction would not convince, however, those antirealists who reject the validity of IBE in general.

\section{The Indispensability Interpretation}

An indispensability argument "purports to establish the truth of some claim based on the indispensability of the claim in question for certain purposes (to be specified by the particular argument)" (Colyvan 2014, fn.1). Indispensability arguments are inter alia used for supporting mathematical Platonism. They state that reference to mathematical entities is indispensable to the practice of mathematics, thus we should commit to their existence (Colyvan 2014). Similar arguments exist in meta-ethics for the reality of moral norms (Enoch 2011).

Structurally, IBE is an indispensability argument, where the indispensable claims are the explanans, and the purpose is explanation. Recall, however, that in this paper, I distinguish 
arguments types on epistemic grounds, rather than structural. Epistemically, IBE and indispensability arguments that are not IBE are of two types, because they confer different types of epistemic warrant on their respective conclusions. As I use the term here, the warrant of IBE is empirical. By contrast, the warrant of indispensability arguments that are not IBE is grounded in the coherence of practical and epistemic rationality; namely, the requirement for consistency between belief and action. If one cannot avoid acting as if $p$ is true, then for the sake of rationality, one should believe that $p$. Otherwise, one is guilty of "intellectual dishonesty" (Putnam 1975, $347) \cdot{ }^{4}$

Some things Hacking writes seem to be in line with an indispensability interpretation of his argument for ER:

The vast majority of experimental physicists are realists about some theoretical entities, namely the ones they use. I claim that they cannot help being so $(1983,262$; italics in the origin, bold added).

As a first approximation, then, Hacking's indispensability argument may be reconstructed as follows:

(IA1) For the purpose of experimentally studying other phenomena we cannot help treat experimental entities as real.

(IA2) Therefore we are rationally compelled to believe that experimental entities exist.

Several difficulties arise with this reconstruction. The first is raised by Hacking himself:

Even if experimenters are realists about entities, it does not follow that they are right. Perhaps it is a matter of psychology: maybe the very skills that make for a great experimenter go with a certain cast of mind that objectifies whatever he thinks about $(1983,265)$.

Hacking's reply to this objection is that experimenters do not believe in the reality of all theoretical entities, only experimental entities. Thus he concludes that experimenters'

\footnotetext{
${ }^{4}$ This is not to deny that an IBE may have a double warrant. I discuss this option in $\S 5$.
} 
compulsion to believe in experimental entities is not psychological $(1983,265)$. Hacking's reply, however, seems unsatisfactory. We may hypothesize that the very skills that make for a great experimenter go with a cast of mind that objectifies whatever she thinks she uses as a tool, and the objection still stands. A second problem with this reconstruction is that the term "we" is ambiguous. Who is rationally compelled to believe in electrons - only experimenters who use them, or the rest of us as well? It does not follow, for instance, from the fact that practicing religious people are rationally compelled to believe in God that everybody else must also believe in God. Third, there is a gap between claiming that it is rationally required to believe that electrons exist (an epistemic claim) to claiming that electrons exist (a metaphysical claim).

A plausible reconstruction that addresses these problems is this:

(IA3) For the purpose of experimentally studying other phenomena, experimental physicists cannot help treat experimental entities (but not other theoretical entities) as real.

(IA4) Therefore, they must rationally believe that experimental entities exist.

(IA4) For forming rational beliefs about which physical entities exists, people who are not experimental physicists must rationally defer to experimental physicists' epistemic authority.

(IA5) Therefore, we must rationally believe that experimental entities exist.

(IA6) What we must rationally believe about physical entities is true.

(IA7) Therefore, experimental entities exist.

This improved reconstruction raises other worries. Regarding (IA4), it is controversial that lay people must rationally defer to experts' epistemic authority. Some argue for it (Hardwig 1985); others reject it (Goldman 2001). Additionally, can't we similarly argue that for forming rational beliefs about religious entities we must rationally defer to clergy's epistemic authority? And why are the relevant experts physicists, rather than philosophers, some of whom are antirealists? (IA6) also seems suspect. If it is derived from a general principle according to which 
what we are rationally compelled to believe is true, it seems too strong. If the claim applies only to physical entities, it seems ad hoc.

I do not wish to give an exhaustive list of prima facie difficulties with the argument. My point is that any plausible indispensability argument for ER would seem to include controversial premises that do not directly bear on the SR debate, such as about when it is rational to defer to expert testimony. Realists should prima facie not commit to any particular stance about such premises. The prospects of developing a robust indispensability argument for ER therefore seem somewhat grim.

\section{The Transcendental Interpretation}

Transcendental arguments have a venerable history in philosophy. They may be described as trying to reverse-engineer reality from appearances. That is, they take as a premise some obvious fact about our mental life and proceeded to claiming that some other state of affairs in reality is a necessary condition for the first one. They aim at revealing the necessary enabling conditions of unquestionable experiences or the unquestionable possession or employment of some kind of knowledge or cognitive ability. They are often used as replies to sceptical claims that question the aspects of reality that the transcendental arguments try to establish. Transcendental arguments proceed from their premises to their conclusion by the preservation of logical or necessary truths (Bardon 2006).

Transcendental arguments, indispensability arguments, and IBEs are sometimes characterized as belonging to an overlapping family of arguments, since they have a similar structure. Within this paper, I distinguish argument types on epistemic grounds, rather than structural, and want to keep the distinction between them clear. Thus, within this family of structurally similar arguments, I call an "IBE" an argument whose epistemic warrant is empirical, an "indispensability argument" an argument whose warrant is grounded in the requirement of consistency between epistemic and practical rationality, and a "transcendental argument" an argument whose epistemic warrant stems from the preservation of logical or necessary truths 
from its premises to its conclusion. The premises of a transcendental argument for SR would typically include some uncontroversial claims about observables, and the conclusion would be to the existence of some unobservables.

If Hacking makes a transcendental argument, it may be to the effect that the existence of electrons and other unobservable experimental entities is a necessary condition for the possibility of the experimental practice in the physics laboratory. Morrison $(1990,17)$, who suggests a transcendental reading of Hacking's argument for ER, interprets his argument as follows:

[T] he argument for realism could perhaps be seen as one which claims that entities and their properties must be presupposed in successful practice; it simply makes no sense to doubt the ontological and epistemological claims that render that practice meaningful. ${ }^{5}$

According to Morrison's transcendental reading, Hacking's argument may be to the effect that "the commitment involved in manipulation is one that, contra antirealists like van Fraassen, involves more than empirical adequacy" $(1990,18)$, Specifically, I suggest that it may be to the effect that the preservation of reference of the term "electron" to electrons (or other unobservable experimental entities) during radical theory changes is a necessary condition for the possibility of the experimental practice Hacking describes. To understand why this may be so, recall the challenge that Kuhn (1970) presents to SR of explaining how reference of unobservable terms is preserved during paradigm shifts, in which their meaning undergoes radical changes. To answer this challenge, Hacking draws on Putnam's causal theory of meaning, according to which the reference of a term is determined by a causal chain to an initial baptizing event of its use, rather than a speaker's understanding of its meaning.

Putnam's theory only explains how the preservation of reference is possible. It is up to Hacking to show that it is preserved. If we draw a parallel to Kant's transcendental arguments,

\footnotetext{
5 According to my taxonomy of argument types, Morrison's interpretation can also be read as an indispensability interpretation
} 
we may interpret Hacking as trying to show this. As Lipton $(2003,216)$ writes, Kuhn and Kant share much in common, but differ in that Kuhn is "Kant on wheels":

The Kantian view is that the truths we can know are truths about a 'phenomenal' world that is the joint product of the 'things in themselves' and the organising, conceptual activity of the human mind. Kuhn, however, is Kant on wheels. Where Kant held that the human contribution to the phenomenal world is invariant, Kuhn's view is that it changes fundamentally across a scientific revolution.

If Hacking indeed employs Kant's methodology of transcendental arguments, it may therefore be for establishing, contra Kuhn, the invariance of reference to experimental entities despite paradigm shifts, similarly to the invariance of Kant's categories.

We may find some hints for a transcendental reading in Hacking's text. Hacking writes that early Kant regarded theoretical entities as part of the noumena, and only later abandoned this view, realizing its inconsistency with his larger philosophy. But then Hacking asks:

What position ought Kant to have taken about theoretical entities that really do some work in science? What would he have done when, in the twentieth century, we learned how to manipulate and even spray electrons and positrons? (1983, 100-101)

Hacking speculates that Kant would not have changed his position, but Hacking may be inclined to take a different stance, and use Kant's own method to prove their existence.

Critically evaluating a transcendental argument for ER is somewhat difficult. The validity of a transcendental argument crucially depends on whether it preserves logical and necessary truths from its premises to its conclusion without smuggling in controversial hidden premises. Thus, evaluating the validity of a transcendental argument requires a careful scrutiny of an elaborate formulation of the argument. But if Hacking's argument is transcendental, he provides at best a suggestive sketch, which is insufficient for such a scrutiny.

Moreover, it is unclear if a transcendental argument can be provided for ER in general, or whether a separate argument should be provided for the existence of every unobservable experimental entity. This is because such an argument must start with an uncontroversial description of an experimental practice at the level of observable entities alone, and then show 
that some conclusions about unobservables logically or necessarily follow from it. Since scientists manipulate entities in many ways and experimental practice significantly varies, it is unclear that a generalized description of scientific experimental practice at the level of observables, which is required for a general transcendental argument for ER, can be provided.

Another difficulty with a transcendental argument for ER is that it is unclear whether its conclusion, namely, that the reality of an unobservable entity is a necessary presupposition for an experimental practice that involves its manipulation, is right in light of apparent empirical examples to the contrary. Morrison (1990, 9-13) describes a case in which physicists manipulated quarks to study charm, while they were still not convinced of the reality of quarks. The consistency of the data they obtained served as a retroactive reason for believing in the existence of both the manipulated and studied entities. For Morrison, this means that "manipulation can occur in context where there are no firmly held beliefs about the entities being manipulated" (1990, 9). Even worse, Gelfert (2003) describes in detail a case in which experimenters manipulate quasi-particles, which they believe to be mere theoretical constructs that do not genuinely exist.

Hacking might object that Morrison's example is a case of the "experimenter's regress" (Collins 1985), where the success conditions for believing that a detector is working properly and that an entity has in fact been detected are logically interdependent. Hacking might object that such a case should not be given in support of SR. Hacking might argue that the case he describes differs from Morrison's quark case in that the success conditions for believing that the detection equipment works properly are logically independent of the conditions for believing that the experiments succeeded. But then, one may wonder what is so special for Hacking about empirical success in the physics laboratory as opposed to other empirical success. What is so special about spraying electrons for studying bosons, which warrants a belief in their existence, as opposed to spraying electrons for producing an image on an old CRT television, which the antirealist can dismantle with her usual argument toolkit? 
There is, however, a prominent criticism of transcendental arguments, to which a transcendental argument for ER should not be susceptible. Transcendental arguments seemingly establish, at most, conclusions about what beliefs are rational or conceptually necessary, but they fall short of establishing conclusions about the external world, as realists would like. Because their premises seemingly concern only subjects' inner world, transcendental arguments cannot warrant conclusions about the external world, since the conclusions should follow only deductively or necessarily (Stroud 1968). Thus, a transcendental argument for SR may be criticised on the grounds that in principle it is not able to establish conclusions about what exists in the external world, including unobservables.

As Grundmann \& Misselhorn (2003) argue, however, it is possible to overcome this problem by introducing into a transcendental argument a minimal premise about the external world that both the realist and antirealist would find unobjectionable, and would function as a bridge principle that establishes a relation between subjective experience and objective reality. Within the $S R$ debate, this suggestion looks promising, because scientific antirealists are not idealists. They deny neither the existence of a mind-independent world (M1), nor that knowledge about observables is possible (Chakravartty 2013). Thus, in principle, it is possible to introduce into a transcendental argument for ER an uncontroversial premise about observables from which some conclusions about unobservables would logically or necessarily follow. For example, an argument may introduce some uncontroversial claims about the "home truths" that are associated with electrons and can be expressed in observable terms alone, such as about their behaviour as charged particles, and derive the existence of electrons, qua unobservable entities, from them.

How do the three interpretations of Hacking's argument that I reviewed so far work together? Do they jointly provide a stronger case for ER than each of them provides alone? The first three arguments seem mutually consistent. They all accept the realist commitments enumerated in $\S 2$. Because they enjoy warrants of different kinds, they implicitly rely on different background assumptions about what makes a claim justified. While different, these 
warrants need not be incompatible with each other; for example, a claim can have both an empirical warrant and follow deductively or necessarily from uncontroversial premises about observables. While, as I have argued, the indispensability argument requires filling in missing premises that concern the argument's own scope and applicability and do not directly bear on the SR debate, there is little reason to think that these premises need to be in tension with the NMA and transcendental arguments. Therefore, the three arguments may work together providing a more robust case for ER than any of them provides alone.

Yet the mutual compatibility and strength of these three arguments depends also on one's general philosophical commitments. Not all scientific realists would be willing to endorse all the three arguments, or any of them. For example, Maddy $(2007,403-405)$ argues that the task of the scientific realist philosopher is critically analyzing and explicating scientists' own detection claims of unobservables, rather than adding an extra layer of philosophical analysis and argumentation to them. Maddy rejects IBEs, transcendental arguments, and indispensability argument for SR, since she views them as adding such an extra layer of philosophical argumentation. Thus, she would not side with any of the three arguments reviewed so far. I think, however, that Maddy is wrong to reject IBE, since scientists' own detection claims are often most charitably interpreted and explicated as IBEs, where the existence of a particular unobservable entity is the best explanation of a particular observable phenomenon. ${ }^{6}$ We should also bear in mind that IBE is a very common form of inference in many non-philosophical contexts (BenMenahem 1990). I therefore believe that at least some IBEs for SR are in line with Maddy's philosophical naturalism. If I am right, then a scientific realist who adheres to Maddy's philosophical methodology might accept the NMA argument for ER, but reject the transcendental and indispensability arguments.

\footnotetext{
${ }^{6}$ In fact, it is hard to interpret Maddy's $(2007,406)$ own explication and analysis of Perrin's argument for the existence of atoms other than as an IBE. Even according to Maddy's own account, Perrin inferred the existence of unobservable atoms from the fact that they produced an observable pattern that was identical to the pattern of Brownian motion of observable entities, where the production of such Brownian motion by atoms had been a novel prediction of statistical thermodynamics.
} 
I have so far suggested three different interpretations of Hacking's argument for ER, which enjoy epistemic warrants of different kinds. I have argued that while different, these interpretations need not necessarily be in tension with each other. In the next two sections, I review two additional interpretations - the Vichian interpretation, and the no-argument interpretation, and argue that they stand in tension with the first three interpretations as well as with each other.

\section{The Vichian Interpretation}

For reviewing the fourth interpretation, consider the following excerpt from Hacking (1983, 247):

The best kinds of evidence for the reality of a postulated or inferred entity is that we can begin to measure it or otherwise understand its causal powers. The best evidence, in turn, that we have this kind of understanding is that we can set out, from scratch, to build machines that will work fairly reliably, taking advantage of this causal nexus.

This echoes Italian philosopher Vico's Maker's Theory of Knowledge. Vico (1668-1744) equates truth with making ("verum ipsum factum"), and argues that inasmuch as we produce something, we also know its causes and understand its true principles. "The verum-factum principle defines knowledge or science as pre-eminently causal in character and as therefore concerned with the genesis or construction of a phenomenon" (Zagorin 1984, 18). ${ }^{7}$

Boon \& Knuuttila (2011) sympathetically read Hacking in this spirit. They interpret Hacking as claiming that a mere mirroring (isomorphism, similarity, etc.) notion of representation, which dominates the philosophy of science, is empty without an intervening component. The epistemic value of models lies in our ability to manipulate them for gaining knowledge about the world or use them to manipulate the world. Boon \& Knuuttila $(2011,87)$ write:

\footnotetext{
${ }^{7}$ I thank Yemima Ben-Menachem for drawing my attention to the resemblance between Hacking and Vico.
} 
...taking a cue from Hacking, we suggest that the representational idiom does not describe adequately our actual theoretical practices, which instead of trying to accurately represent the world, are more tuned to our active engagement with the world than what is customarily supposed.

We may reconstruct Hacking's Vichian argument as follows:

(VA1) Experimenters reliably produce phenomena by manipulating the causal powers of electrons.

(VA2) Having such causal manipulative abilities is a sufficient condition for having knowledge of electrons, where knowledge entails truth.

(VA3) Having knowledge of electrons entails having knowledge that electrons exist.

(VA4) Therefore, experimenters know that electrons exist.

(VA5) Therefore, electrons exist.

The warrant of this argument is grounded in whatever principles underlie Vico's Maker Theory of Knowledge. Thus, (VA2) seems to carry the epistemic weight of the argument. Vico thinks that humans can only have knowledge of the human world, because only God produces natural phenomena. As Carrier (2011, 48-52) argues, however, we nowadays study nonnaturally occurring phenomena of our own making, and use them to study other phenomena as well. Carrier doubts, however, that causal manipulative abilities are sufficient for knowledge for two reasons. First, sometimes scientists know how to produce certain effects without fully understanding the underling causal dynamics at play. Second, manipulative ability is usually consistently achieved under certain background conditions, and scientists do not always know how changing them would affect the outcome.

The Vichian argument does not square nicely with the first three interpretations or with the standard realist commitments. Vico's equation of truth with making violates SR commitment to a non-epistemic theory of truth (S2). That is, the Vichian argument is framed within an anthropocentric epistemology that equates truth with making, yet realists hold that the truth values of claims is independent of the human ability to test or verify them. According to Hacking, 
his own ER can be expressed in terms of a correspondence theory of truth or something like it (1988, 291).

Moreover, a Vichian framework forms a hierarchy of knowability, which seems incompatible with the hierarchy assumed within the SR debate. Though many argue that the lines between observable and unobservable entities are blurry, it is still generally assumed within the SR debate that observable entities are on more secure epistemic grounds than unobservable. That is, all sides to the debate accept that we have knowledge of observables, and the debate concerns unobservables. Manipulability draws the epistemic lines differently from observability. It places manipulatable entities, such as unobservable electrons and observable car engines, higher on its epistemic hierarchy than non-manipulatable entities, such as unobservable bosons and observable hurricanes.

I do not suggest that a Vichian epistemology and the standard SR assumptions cannot be reconciled with each other if one has enough philosophical motivation and free time. Such a reconciliation, however, would have to significantly relax the realist commitments, to an extent that it would be unclear if ER could still legitimately be called "realism", bearing in mind that because ER is antirealist about theories, it is already a modest realist position. Alternatively, such a reconciliation would take the wind out of the Maker's Theory of Knowledge, because it would have to relax its anthropocentric focus, which makes it attractive to begin with. Thus, a robust case for ER that includes a Vichian line of argument seems unpromising.

\section{The Non-Argument Interpretation}

The last interpretation of Hacking's argument is that it is not an argument at all, as Hacking does not think that an argument can establish the reality of electrons. Rather, the experimental practice directly illustrates their reality. According to this interpretation, the epistemic warrant for ER lies in directly perceiving the laboratory practice, rather than any feature of an argument for it. According to this reading, the roots of Hacking's (non) argument 
lie in the anti-theoretical traditions of pragmatism and in the commonsensical reaction to Berkeley's idealism made famous by Samuel Johnson. When Johnson manipulated a stone with his foot he at once affirmed that the stone was more than a mere theoretical construct and that he was warranted in applying commonsense reasoning to affirm its existence (Lyons and Clarke 2002, xx-xxi).

This reading accords with the fact that Hacking does not give an explicit argument for ER, but gives a detailed vivid description of the experimental practice in the physics laboratory. It also accords with Hacking's depiction of his conversation with a physicist, in which the physicist said physicists spray positrons, and after which Hacking became a realist $(1983,23)$.

In suggesting this interpretation, I follow Greco's interpretation of Moore's famous proof of an external world, in which Moore $(1962,144)$ gestures with his hands while saying "here is one hand" and "here is another", and then deduces the existence of an external world. Greco (2002) argues that the epistemic force of Moore's proof does not lie in any feature of Moore's argument, but in the direct perception of an undeniable fact, i.e., Moore's hands. Greco reads Moore's argument as playful, where Moore's very point is that we do not know that external things exist by proving this, but by perceiving them. This is similar to Brown's (1997) claim that some pictures constitute in and by themselves mathematical proofs, because they allow people to directly perceive the truth of a mathematical theorem, without needing to translate them to, or accompany them with an argument.

This interpretation does not require a reconstruction, but we may follow Greco's Moore and give the following reconstruction, which should be read playfully:

(NA1) Experimenters spray electrons.

(NA2) Therefore, electrons exist.

The non-argument interpretation returns SR to its common-sense roots. Before SR shattered into countless positions with hair-splitting epistemic and ontic distinctions between them, it was considered a common-sense philosophy, which takes our best science at its face value, and elucidates scientists' own philosophy. In particular, it was the common-sense 
response to logical empiricists' elaborate take on scientific claims, their truth, and their meaning. Yet, one may question the commonsensical status of knowledge of unobservable entities, such as electrons, as opposed to observable entities, such as Moore's hands. In response, Hacking may argue that for experimenters and those who study them, knowledge of electrons becomes as commonsensical as knowledge of one's hands. The prospects of such a suggestion need further exploring.

There are difficulties reconciling the non-argument argument for ER with the rest. As Morrison observes, if we accept the transcendental interpretation, "we must dismiss Hacking's claim that manipulation offers direct proof of the reality of entities" $(1990,18)$. The same would apply to all the rest of the interpretations too. According to the non-argument interpretation, the rest of the arguments commit a category mistake: they try to prove with a philosophical argument what can only be proven with a direct unmediated physical demonstration. The non-argument interpretation, then, nullifies any other philosophical arguments for ER. It thus cannot be integrated within a robust case for ER.

\section{Conclusion}

While Hacking's catchy slogan "if you can spray them then they are real" seems intuitive and persuasive, and Hacking's argument for Entity Realism seems simple and straightforward, appearances can be misleading. I distinguished five possible readings of Hacking's argument for Entity Realism based on the epistemic rationale that underlies them: (1) a no-miracles argument, whose epistemic warrant is empirical; (2) an indispensability argument, whose warrant is grounded in the requirement of consistency between epistemic and practical rationality; (3) a transcendental argument, whose warrant is grounded in the preservation of logical or necessary truths from a set of uncontroversial premises to its conclusion; (4) a Vichian argument, whose warrant is grounded in an epistemology in the spirit of Vico's Maker's Theory of Knowledge, which connects truth with making; (5) a non-argument, where the epistemic warrant does not lie in any feature of a philosophical argument for Entity Realism, but in the direct unmediated 
demonstration power of the experimental practice in the physics laboratory. The version of the argument a scientific realist would like to side with, if any, depends on deep issues at the heart of the debate, such as the nature of truth, representation, and knowledge.

\section{Acknowledgements}

I thank Anjan Chakravartty, Jacob Stegenga, Yemima Ben-Menachem, and Daniel Steel for helpful comments and discussions. This paper was presented at the Israel Society for History and Philosophy of Science Annual Meeting, Jerusalem, 2013, and at the PSA Biennial Meeting, Chicago, 2014. I thank the audience members for helpful comments. I am grateful to the students at my seminar in philosophy of science at the Bar Ilan University Graduate Program in Science, Technology, and Society for realizing that getting at the bottom of Hacking's argument is tricky. I thank the Dan David Foundation, the Cohn Institute for the History and Philosophy of Science and Ideas, Tel Aviv University, and the Sidney M. Edelstein Center for History and Philosophy of Science, Technology and Medicine, the Hebrew University of Jerusalem, for postdoctoral fellowships.

\section{References}

Bardon, Adrian. 2006. "Transcendental Arguments." In The Internet Encyclopedia of Philosophy, ed. James Fieser \& Bradley Dowden. http://www.iep.utm.edu/trans-ar/

Ben-Menahem, Yemima. 1990. "Inference to the Best Explanation”. Erkenntnis 33: 319-334.

Boon, Mieke \& Tarja Knuuttila. 2011. "Breaking Up with the Epochal Break: The Case of Engineering Sciences." In Science Transformed? Debating Claims of an Epochal Break, eds. Alfred Nordmann, Hans Radder \& Gregor Schiemann, 86-79. Pittsburgh, PA: University of Pittsburgh Press.

Brown, James R. 1997. "Proofs and Pictures." British Journal for the Philosophy of Science 48(2): 161-180.

Carrier, Martin. 2011. “'Knowledge Is Power,' or How to Capture the Relationship between Science and Technoscience." In Science Transformed? Debating Claims of an Epochal Break, eds. Alfred Nordmann, Hans Radder, \& Gregor Schiemann, 43-53. Pittsburgh, PA: University of Pittsburgh Press.

Cartwright, Nancy. 1983. How the Laws of Physics Lie. Oxford: Clarendon Press.

Chakravartty, Anjan. 2007. A Metaphysics for Scientific Realism: Knowing the Unobservable. Cambridge: Cambridge UP.

Chakravartty, Anjan. 2013. "Scientific Realism." In The Stanford Encyclopedia of Philosophy, ed. Edward N. Zalta. http://plato.stanford.edu/entries/scientific-realism/ 
Collins, Harry. 1985. Changing Order: Replication and Induction in Scientific Practice. Chicago: University of Chicago Press.

Colyvan, Mark. 204. "Indispensability Arguments in the Philosophy of Mathematics." In The Stanford Encyclopedia of Philosophy, ed. Edward N. Zalta. http://plato.stanford.edu/entries/mathphil-indis/

Day, Timothy \& Harold Kincaid. (1994). "Putting Inference to the Best Explanation in its Place." Synthese 98(2): 271-295.

Enoch, David. 2011. Taking Morality Seriously: A Defense of Robust Realism. Oxford: OUP.

Gelfert, Axel. 2003. "Manipulative Success and the Unreal". International Studies in the Philosophy of Science 17(3): 245-263.

Giere, Ronald. 1988. Explaining Science: A Cognitive Approach. Chicago: University of Chicago Press.

Goldman, Alvin I. 2001. “Experts: Which Ones Should You Trust?” Philosophy and Phenomenological Research 63(1): 85-111.

Greco, John. 2002. "How to Reid Moore”. The Philosophical Quarterly 52(209): 544-563.

Grundmann, Thomas \& Catrin Misselhorn. 2003. "Transcendental Arguments and Realism." In Strawson and Kant, ed. Hans-Johann Glock, 205-218. Oxford: Oxford UP.

Hacking, Ian. 1983. Representing and Intervening: Introductory Topics in the Philosophy of Natural Science. Cambridge: Cambridge UP.

Hacking, Ian. 1988. "The Participant Irrealist At Large in the Laboratory". British Journal for the Philosophy of Science 39(3): 277-294.

Hacking, Ian. 1989. "Extragalactic Reality: The Case of Gravitational Lensing." Philosophy of Science 56(4): 555-581.

Hardwig, John. 1985. “Epistemic Dependence.” The Journal of Philosophy 82(7): 335-349.

Kitcher, Philip. 1993. The Advancement of Science: Science without Legend, Objectivity without Illusions. Oxford: Oxford UP.

Kuhn, Thomas S. 1970. The Structure of Scientific Revolutions, $2^{\text {nd }}$ ed. Chicago: University of Chicago Press.

Ladyman, James. "Structural Realism." In The Stanford Encyclopedia of Philosophy, ed. Edward N. Zalta. http://plato.stanford.edu/entries/structural-realism/

Lehoux, Daryn. 2012. What Did the Romans Know? An Inquiry into Science and Worldmaking. Chicago: University of Chicago Press. 
Lipton, Peter. 2003. “Kant on Wheels.” Social Epistemology 17(2\&3): 215-219.

Lipton, Peter. 2004. Inference to the Best Explanation, $2^{\text {nd }}$ ed. London: Routledge.

Lyons, Timothy D. \& Steve Clarke. 2002. "Introduction: Scientific Realism and Commonsense." In Scientific Realism and Commonsense, eds. Steve Clarke \& Timothy D. Lyons, ix-xxiii. Dordrecht: Kluwer.

Maddy, Penelope. 2007. Second Philosophy: A Naturalistic Method. Oxford: OUP.

Moore, George E. 1962. "Proof of an External World". In Philosophical Papers, 126-148. New York: Collier Books.

Morrison, Margaret. 1990. “Theory, Intervention and Realism.” Synthese 82(1): 1-22.

Putnam, Hilary. 1975. Mathematics, Matter and Method. Cambridge: Cambridge UP.

Solomon, Miriam. 2001. Social Empiricism. Cambridge, MA: MIT Press.

Stroud, Barry. 1968. “Transcendental Arguments.” The Journal of Philosophy 65(9): 241-256.

Zagorin, Perez. 1984. “Vico's Theory of Knowledge: A Critique." The Philosophical Quarterly 34(134): 15-30. 